NASA Technical Memorandum 89016

\title{
SOLUBLE AROMATIC POLYIMIDES FOR FILM COATING APPLICATIONS
}

Anne K. St. Clair and Terry L. St. Clair

September 1986

\footnotetext{
(NASA-TM-89016) SCLUBIE AECKAIC POLYIMIDES FOR FILM AND COAIING AFELICAIICAS (NASA)

$11 \mathrm{p}$

CSCL 11B
}

N87-16911

Unclas

G3/27 43977 


\section{SOLUBLE AROMATIC POLYIMIDES FOR FILM AND COATING APPLICATIONS}

\section{Anne K. St. Clair and Terry L. St. Clair Materials Division NASA Langley Research Center Hampton, Virginia 23665-5225}

\section{INTRODUCTION}

Because of their toughness, flexibility and remarkable thermal stability, linear all-aromatic polyimides are excellent candidate film and coating materials for advanced electronic circuitry and wire coating applications. In past years, however, the inherent insolubility $(1,2)$ of these polymers has somewhat limited their usefulness for electronic applications.

The classic approach of infcorporating aromatic pendant groups along the polymer backbone has been used successfully to improve the solubility of linear polyimides. (3-5) Variation in the isomeric points of attachment of bridging groups in the diamine monomers has also proved effective at enhancing solubility of polyimides in common organic solvents. (6) More recently, the combined effects of incorporating bulky $\left(-\mathrm{CF}_{3}\right.$ and $\left.-\mathrm{SO}_{2}\right)$ groups, 1 inking or bridging groups, and meta-linked diamines to reduce charge transfer complexing in aromatic polyimides and thereby facilitate solubility have been studied. (7) other researchers have al so reported the solubility of polyimides prepared with biphenyltetracarboxlic dianhydrides in a high-boiling solvent, N-methyl prol idone. $(8,9)$

The purpose of this investigation was to observe the effects on solubility of changing isomeric points of attachment of phenoxy units in the diamine portion of several all-aromatic polyimide systems. Hexafluoropropane- and oxygencontaining dianhydrides were used in this study because of their known value at contributing to polyimide solubility. $(6,7)$ 


\section{EXPERIMENTAL}

Materials

The 4,4'-oxidiphthalic anhydride (ODPA) was recrystallized from anisole and sublimed at $200^{\circ}-210^{\circ} \mathrm{C} / 1 \mathrm{~mm}$ prior to use (m.p. $\left.224^{\circ} \mathrm{C}\right)$. The 2,2-bis $(3,4-$ dicarboxphenyl)hexafluoropropane dianhydride (6F) was obtained from American Hoechst and recrystallized from toluene/acetic anhydride (m.p. $241^{\circ} \mathrm{C}$ ). The $4,4^{\prime}$-oxydianiline $\left(4,4^{\prime}-0 D A\right)$ was obtained commercially, recrystallized and sublimed (m.p. $188^{\circ} \mathrm{C}$ ). The $3,4^{\prime}-$ and $3,3^{\prime}$-oxydianiline diamines $\left(3,4^{\prime}-00 \mathrm{~A}\right.$ and 3,3'-ODA) are experimental materials obtained from Mitsui Toatsu, Inc. The $3,4^{\prime}-O D A$ was recrystallized (m.p. $74^{\circ} \mathrm{C}$ ); and the $3,3^{\prime}$-ODA was vacuum distilled at $125^{\circ} \mathrm{C} / 0.1 \mathrm{~mm}\left(\mathrm{~m} . \mathrm{p} .77^{\circ} \mathrm{C}\right)$. Source and purity of the $2,4^{\prime}-00 \mathrm{~A}$ has been reported $(10)$ el sewhere. The 1,4-bis(4-aminophenoxy) benzene, 1,4(4)APB; 1,3-bis(4-aminophenoxy)benezene, 1,3(4)-APB; and 1,4-bis(3-aminophenoxylbenezene, 1,4(3)-APB, were experimental diamines obtained and used as received from Mitsui Toatsu, Inc., with melting points of $171^{\circ}, 115^{\circ}$, and $127^{\circ}$ respectively. The 1,3-bis(3-aminophenoxy)benezene, 1,3(3)-APB, was obtained commercially (m.p. $105^{\circ} \mathrm{C}$ ). Dimethylacetamide (DMAC) used as a solvent for polymerization was vacuum distilled at $107^{\circ} \mathrm{C}$ over calcium hydride.

\section{Preparation of Polymers}

Polyamic acids were prepared at $15 \%$ solids $(w / w)$ by adding the diamine and DMAC to a flask flushed with dry nitrogen. An equimolar amount of solid dianhydride was then added to the dissolved diamine. After stirring 8-24 hours at room temperature, the resulting polyamic acid solutions were refrigerated. Films were prepared by casting the amic acid resins onto sodalime glass plates in an enclosed dust-free chamber at $10 \%$ relative humidity. Films were cured unless otherwise indicated by heating in a forced air oven for one hour each at $100^{\circ}, 200^{\circ}$ and $300^{\circ} \mathrm{C}$. Resulting polyimide films were approximately $1 \mathrm{mil}(.0025 \mathrm{~cm})$ in thickness. 


\section{Characterization}

Melting points were determined on an E. I. DuPont Series 99 Thermal Analyzer at $20^{\circ} \mathrm{C} / \mathrm{min}$. Inherent viscosities of polyamic acid solutions were obtained at a concentration of $0.5 \%(w / w)$ in DMAC at $35^{\circ} \mathrm{C}$. Glass transition temperatures $\left(T_{g}\right)$ of the fully cured polymer films were measured by thermomechanical analysis (TMA) on a DuPont 943 Analyzer in air at $5^{\circ} \mathrm{C} / \mathrm{min}$. Films fully-cured at $300^{\circ} \mathrm{C}$ were tested for solubility at $3-5 \%(w / w)$ solids concentration in DMAC, $\mathrm{N}, \mathrm{N}$-dimethyl formamide (DMF), and chloroform $\left(\mathrm{CHCl}_{3}\right)$. Solubilities at room temperature were noted after periods of 3 hours, 1 day and 5 days. Refractive indices of 1 mil thick films were obtained at ambient temperature by the Becke line method (11) using a polarizing microscope and standard immersion liquids obtained from R. P. Cargille Labs.

\section{RESULTS AND DISCUSSION}

The polyimide films prepared from the mononers shown in Figures 1-3 are listed in Table I. Reaction of monomers yielded pale yellow to colorless polyamic acid solutions with inherent viscosities ranging from 0.34 to $1.82 \mathrm{dl} / \mathrm{g}$. Tough, flexible, transparent films were produced by thermally converting the polyamic acids to polyimides at $300^{\circ} \mathrm{C}$ in air. Films ranged in color from a light yellow color to essentially colorless depending on thickness. The film colors described in Table I were for nominally 1 mil thick films. Glass transition temperatures of films increased in value within each series of polymers as the linkages of the aromatic diamines were varied from al1-meta to a11para. Polyimides prepared with 6F dianhydride consistently displayed higher $\mathrm{T}_{\mathrm{g}}$ than did ODPA dianhydride-containing polymers with the same diamine. The ODPA 
films had a higher refractive index $(n=1.67-1.69)$ than did the $6 \mathrm{~F}$ polymers $n=1.60-1.62)$. Refractive indices for these series of films was governed by the dianhydride portion of the polymer chain. These values of refractive index are all lower than the reported values of commercial polyimide film (1.78).

The solubilities of polyimide films cured at $300^{\circ} \mathrm{C}$ are presented in Tables II and III. Polymers prepared with ODPA dianhydride were less soluble overall in the solvents 1 isted than those prepared with $6 \mathrm{~F}$. This phenomenon is not surprising as the $6 \mathrm{~F}$ dianhydride because of its bulky -CF 3 groups is most effective in preventing charge transfer complexing (CTC) between polymers chains through steric hindrance. (7). ODPA containing oxygen as a "separator" or "linking atom" is also effective (although less so than 6F) in producing a reduction in CTC when compared to pyromellitic (PMDA) or benzophenone tetracarboxylic (BTDA) dianydrides. When coupled with the diamines in Figure 2 , these latter two dianydrides produce totally insoluble polymers.

The polyimides prepared with $6 F$ dianhydride (Table II) were exceedingly soluble in the solvents studied. Solubility increased with incorporation of meta or ortho isomerism which serves to create more "kinks" and disymmetry in the polymer chains. The same trend was observed for ODPA-containing films (Table III) except to a lesser degree. Ortho isomerism appeared to have a greater effect on the solubility of ODPA films than did meta isomerism as had been noted previously. (6)

Several polymers were tested for solubility at high concentrations of polymer in the solvent. Previous studies had shown that ODPA + $0, p^{\prime}-O D A$ and $6 F+0, p^{\prime}-O D A$ films had a high degree of solubility in DMF at room temperature $(>40 \% \mathrm{w} / \mathrm{w})$. (6) The polyimide powder of $6 F+3,3^{\prime}-O D A$ was likewise tested for its solubility limit 
in DMAC. The imide powder was prepared by chemically imidizing the $6 \mathrm{~F}+3,3^{\prime}-0 D A$ polyamic acid with pyridine/acetic anhydride, precipitating in distilled water, thoroughly drying at $60^{\circ} \mathrm{C}$ and heating for 2 hours at $200^{\circ} \mathrm{C}$. This powder was gradually added to DMAC while stirring. After dissolving amounts greater than $30 \%$ (w/w) stirring became so difficult, the experiment was stopped.

Another method for solubilizing polyimide film by curing the polyamic acid for longer times at lower temperatures was attempted. The $6 \mathrm{~F}+4,4^{\prime}-$ ODA film cured 1 hour at $300^{\circ} \mathrm{C}$ was found to be insoluble in DMAC at ambient temperature. The same material cured for 5 hours at $200^{\circ} \mathrm{C}$ was totally soluble in DMAC upon stirring for several hours. Although the $\mathrm{T}_{g}$ of this polymer was $10-15^{\circ} \mathrm{C}$ lower than that of the polymer cured at $300^{\circ} \mathrm{C}$, the infrared spectrum of the film showed only a slight hint of anhydride $-C=0$ peak.

\section{CONCLUSIONS}

Soluble all-aromatic polyimides have been produced by coupling hexafluoropropane-(6F) and oxygen-(ODPA) containing dianhydrides with oxydianiline and bis(aminophenoxy)benezene diamines. Solubility was enhanced by the presence of meta and ortho isomer links in the diamine portion of the molecule. The polymers prepared with $3,3^{\prime}-O D A$ and $2,4^{\prime}-O D A$ were found to be readily soluble at $>30-40 \%$ solids at room temperature in amide solvents. These polyimides are al so readily soluble in low-boiling chlorinated solvents. They can therefore be spray-coated onto desired substrates in the fully-imidized form and thus eliminate the need for taking the substrate to elevated temperatures. These soluble phenoxy-linked polyimides yield tough, flexible, colorless to pale yellow transparent films from amide or cholorinated solvents. Their potential for use in electronic applications should be excellent. 


\section{REFERENCES}

1. Adrova, N. A., Bessonov, M. I., Laius, L. A. and Rudakov, A. P., "Polyimides, A New Class of Thermally Stable Polymers," Technomic Publishing Co., Stamford, CT, P. 89, 1970.

2. Sroog, C. E., Endrey, A. L., Abramo, S. V., Berr, C. E., Edwards, W. M., and 01 ivier, K. L., J. Polym. Sci., A, 3, 1373 (1965).

3. Korshak, V. V., Vinogradova, S. V. and Vygodskii, Y. S., J. Macromol. Sci. - Rev. Macromol. Chem., C-11 (1), 45 (1974).

4. Harris, F. W., Feld, W. A. and Lanier, L. H., Polymer Letters Edition, 13, 283, (1975).

5. Harris, F. W., Norris, S., Lanier, L., Reinhardt, B., Case, R., Varaprath, S., Padaki, S., Torres, M., and Feld, W., "Polyimides," ed. K. L. Mittal, Plenum Press, NY, Vol. 1, p. 3, 1984.

6. St. Clair, T. L., St. Clair, A. K., and Smith, E. N., "Structure-Solubility Relationships in Polymers," ed. F.W. Harris and R. B. Seymour, Academic Press, Inc., New York, NY, p. 199, 1977.

7. St. Clair, A. K., St. Clair, T. L., Slemp, W. S. and Ezzell, K. S., Proceedings of the 2nd International Conference on Polyimides, Ellenville, NY, p. 333, (1985); NASA-TM-81650.

8. Nakano, T., Proceedings of the 2nd International Conference on Polyimides, Ellenville, NY, p. 163 (1985).

9. Yamane, H., Proceedings of the 2nd International Conference on Polyimides, Ellenville, NY, P. 86 (1985).

10. Bell, V.. L., Stump, B. L. and Gayer, H., J. Polymer Sci.: Polym. Chem. Ed., A-1, 14, 2275 (1976).

11. Faust, R. C., Proc. Phys. Soc., 68B, 1081 (1955).

\section{ACKNOWLEDGEMENTS}

The authors are indebted to Mr. Robert Ely for his expert technical assistance and Mr. Edward Shockey for refractive index measurements. 
<smiles>O=C1OC(=O)c2cc(C(F)(F)C(F)(F)F)ccc21</smiles><smiles>O=C1OC(=O)c2cc(Oc3ccc4c(c3)C(=O)OC4=O)ccc21</smiles>

Figure 1 Dianhydride Honomers<smiles>Nc1cccc(Oc2cccc(N)c2)c1</smiles>

3, 3-ODA 2, 4-ODA $3,4-O D A$ 4,4-ODA

$$
\begin{array}{cc}
1,4(4)-A P B & 1,3(4)-A P B \\
1,4(3)-A P B & 1,3(3)-A P B
\end{array}
$$

Figure 2 Oxydianiline Diamines

Figure 3 Aminophenoxybenzene Diamines 
TABLE I. Properties of Polyimide Films

\begin{tabular}{|c|c|c|c|c|}
\hline Polymer & $\begin{array}{l}n_{\text {inh }} \\
(d 1 / g)\end{array}$ & $T_{g}$, oC & $\begin{array}{l}\text { Refractive } \\
\text { Index }(n)\end{array}$ & Film Appearance \\
\hline $6 \mathrm{~F}+3,3^{\prime}-0 \mathrm{DA}$ & 1.00 & 244 & 1.60 & Pale to Colorless \\
\hline $6 F+2,4^{\prime}-00 A$ & 0.75 & 276 & - & Pale to Colorless \\
\hline $6 F+3,4^{\prime}-0 D A$ & 0.79 & 280 & 1.60 & Pale Yellow \\
\hline $6 F+4,4^{\prime}-0 D A$ & 1.11 & 326 & 1.60 & Pale Yellow \\
\hline$O D P A+3,3^{\prime}-O D A$ & 1.09 & 186 & 1.69 & Pale to Colorless \\
\hline$O D P A+2,4^{\prime}-O D A$ & 0.77 & 264 & 1.67 & Pale to Colorless \\
\hline$O D P A+3,4^{\prime}-O D P A$ & 0.61 & 245 & 1.69 & Pale Yellow \\
\hline$O D P A+4,4^{\prime}-O D A$ & 0.34 & 273 & 1.69 & Light Yellow \\
\hline $6 F+1,4(4)-A P B$ & 1.82 & 281 & 1.60 & Light Yellow \\
\hline $6 F+1,3(4)-A P B$ & 1.58 & 255 & 1.62 & Light Yellow \\
\hline $6 F+1,4(3)-A P B$ & 1.19 & 230 & 1.61 & Pale to Colorless \\
\hline $6 F+1,3(3)-A P B$ & 1.02 & 209 & 1.61 & Pale to Colorless \\
\hline$O D P A+1,4(4)-A P B$ & 1.46 & 245 & 1.67 & Light Yellow \\
\hline$O D P A+1,3(4)-A P B$ & 1.29 & 217 & 1.69 & Light Yellow \\
\hline$O D P A+1,4(3)-A P B$ & 1.06 & 204 & 1.68 & Pale Yellow \\
\hline$O D P A+1,3(3)-A P B$ & 0.98 & 182 & 1.68 & Pale to Colorless \\
\hline
\end{tabular}


Table II. Solubilities of Polyimide Films Prepared with 6F Dianhydride $a, b$

\begin{tabular}{|c|c|c|c|c|c|c|c|c|c|}
\hline Diamine & $3 h r$ & $\begin{array}{l}\text { DMAC } \\
1 d\end{array}$ & $5 d$ & $3 \mathrm{hr}$ & $\begin{array}{l}\text { DMF } \\
\text { Id }\end{array}$ & $3 d$ & $\begin{array}{c}\mathrm{CHCl}_{3} \\
3 \mathrm{hr}\end{array}$ & Id & $5 d$ \\
\hline $3,3^{\prime}-O D A$ & $\mathbf{s}$ & s & $s$ & $s$ & s & 5 & $\mathbf{s}$ & s & $s$ \\
\hline $2,4^{\prime}-O D A$ & $s$ & $s$ & $s$ & $s$ & $\mathrm{~s}$ & $s$ & 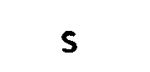 & s & $\mathrm{s}$ \\
\hline $3,4^{\prime}-0 D A$ & $\mathrm{i}$ & $s$ & s & $\mathrm{i}$ & $\mathrm{s}$ & $s$ & $i$ & $\mathbf{s}$ & s \\
\hline $4,4^{\prime}-00 A$ & $\mathrm{i}$ & $i$ & $\mathbf{i}$ & i & $s$ & $s$ & $\mathbf{i}$ & s & $s$ \\
\hline $1,4(4)-A P B$ & $\mathbf{i}$ & $\mathbf{i}$ & $\mathbf{i}$ & $\mathbf{i}$ & s & $s$ & $\mathbf{i}$ & s & $s$ \\
\hline $1,3(4)-A P B$ & $s$ & s & s & s & $\mathrm{s}$ & $s$ & s & s & $s$ \\
\hline $1,4(3)-A P B$ & ps & $\mathrm{s}$ & s & ps & ps & ps & ps & ps & ps \\
\hline $1,3(3)-A P B$ & $s$ & $s$ & $s$ & s & s & $s$ & s & s & s \\
\hline
\end{tabular}

${ }^{a}$ Solubilities were tested after 3 hours, 1 day and 5 days at room temperature

$b_{s}=$ totally soluble; ps = partly soluble; $i=$ insoluble

Table III. Solubilities of Polyimide Films Prepared with ODPA Dianydride

\begin{tabular}{|c|c|c|c|c|c|c|c|c|c|}
\hline Diamine & $3 \mathrm{hr}$ & $\begin{array}{l}\text { DMAC } \\
1 d\end{array}$ & & $5 d$ & $\begin{array}{l}\text { DMF } \\
1 \mathrm{~d}\end{array}$ & $3 d$ & $3 \mathrm{hr}$ & $\underset{1 \mathrm{~d}}{\mathrm{CHCl}_{3}}$ & $5 d$ \\
\hline $3,3^{\prime}-O D A$ & $\mathbf{i}$ & s & $s$ & $\mathrm{i}$ & $\mathrm{i}$ & $\mathbf{i}$ & s & $\mathrm{s}$ & $s$ \\
\hline $2,3^{\prime}-O D A$ & $s$ & $s$ & $s$ & $s$ & s & $\mathrm{s}$ & - & - & - \\
\hline $3,4^{\prime}-O D A$ & $\mathbf{i}$ & $i$ & $i$ & $\mathrm{i}$ & $i$ & $\mathbf{i}$ & $\mathbf{i}$ & $i$ & $i$ \\
\hline $4,4^{\prime}-0 D A$ & & $i$ & $i$ & $i$ & $i$ & $i$ & $\mathbf{i}$ & $i$ & $\mathbf{i}$ \\
\hline $1,4(4)-A P B$ & $\mathbf{i}$ & $\mathbf{i}$ & $i$ & i & $\mathrm{i}$ & $\mathbf{i}$ & $i$ & i & $i$ \\
\hline $1,3(4)-A P B$ & $\mathbf{i}$ & $\mathbf{i}$ & $i$ & $i$ & $i$ & $\mathrm{i}$ & $\mathbf{i}$ & $\mathrm{i}$ & $\mathbf{i}$ \\
\hline $1,4(3)-A P B$ & $\mathbf{i}$ & $\mathrm{i}$ & i & $\mathrm{i}$ & $i$ & $\mathbf{i}$ & $i$ & $i$ & $i$ \\
\hline $1,3(3)-A P B$ & ps & ps & ps & ps & ps & ps & ps & ps & ps \\
\hline
\end{tabular}




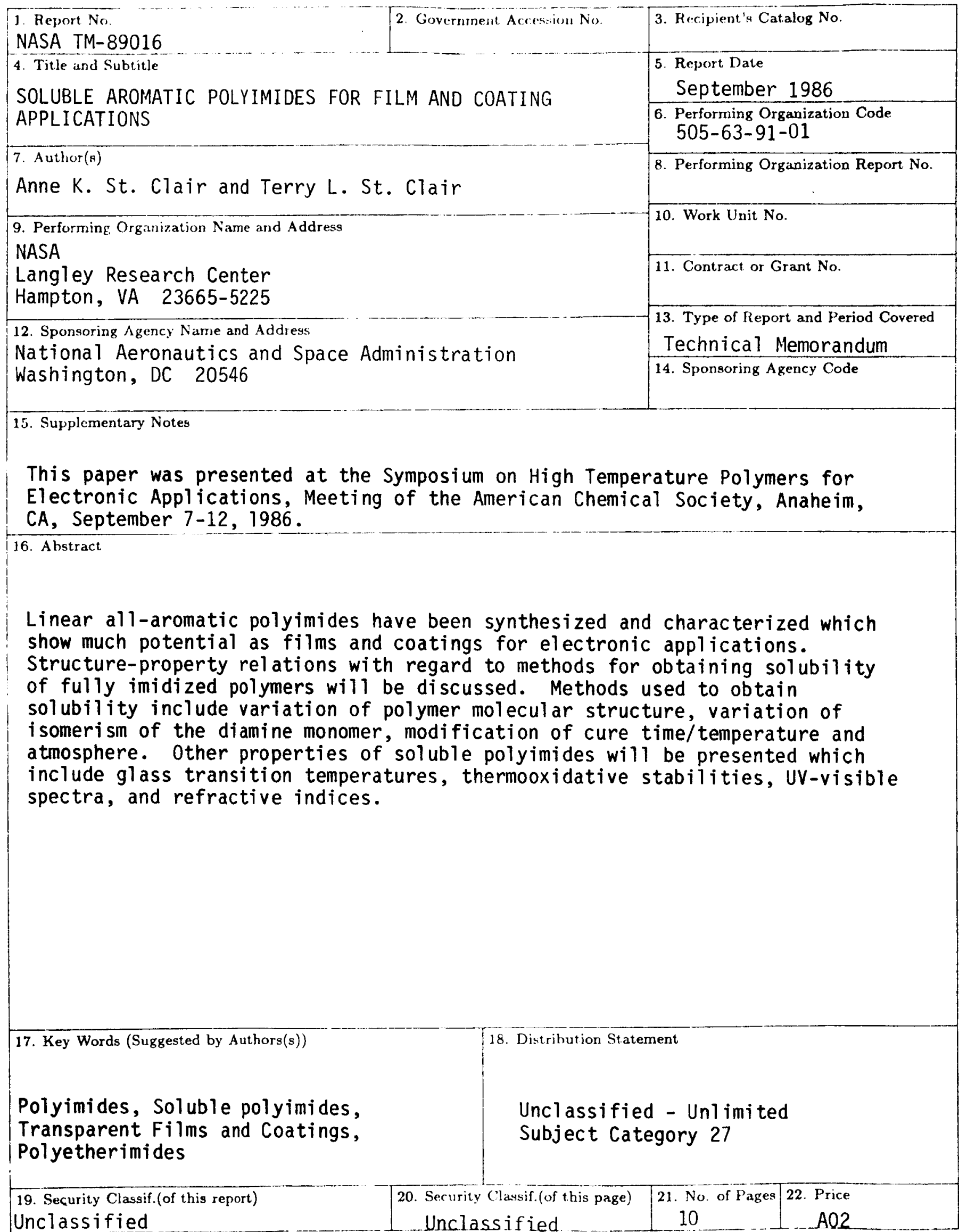

Unclassified 